\title{
The Effect of a Pediatric Rare Disease on Subscriber Retention Rates for Commercial Health Insurers in the United States
}

\author{
Melanie K. Kuester, PharmD, BCPS; E. Anne Jackson, FSA, MAAA; Brenda M. Runyan, MBA; \\ Edmund J. Pezalla, MD, MPH; and Samuel R. Nussbaum, MD
}

\begin{abstract}
BACKGROUND: The advent of personalized medicine creates opportunities for regenerative therapies to deliver extended clinical benefit from a single administration. Policymakers and health insurers in the United States are evaluating coverage and payment arrangements for these therapies. One challenge involved in these evaluations is the perception that subscribers change insurers relatively often. However, the effect of pediatric rare diseases on retention rates for commercial health insurers has not been well studied.

OBJECTIVE: To develop estimates for subscriber retention by a commercial insurer for up to 10 years.

METHODS: Three population cohorts were examined: (1) all subscribers, (2) subscribers with any dependent aged 16 years or younger, and (3) subscribers with any dependent aged 16 years or younger diagnosed with a chronic rare disease that typically results in a debilitating state or high mortality, usually associated with high health care costs regardless of whether a treatment is available. The analysis was conducted for a sample of fully insured and self-insured group business within the commercial health insurance market for these study cohorts. The MarketScan Commercial Claims and Encounters research database covering the time period from January 1, 2007, through December 31, 2016, was used as the basis for the analysis. Subscribers were included in the family-based cohorts beginning with the first observed month with a dependent aged 16 years or younger and were retained in the analysis until the subscriber or insurer withdrew from the dataset (whichever came first). Subscribers were included in the family-based rare disease cohorts if their qualifying dependent was reported with at least 2 occurrences for any of the rare diseases studied. A Kaplan-Meier estimator was used to produce retention rates for all populations for up to 120 months. An adjustment for interval censoring was applied to the family-based cohorts. A log rank test with chi-square statistic was used to determine statistical significance.
\end{abstract}

RESULTS: The analysis found that the subscriber retention rate within the self-insured groups was higher than within the fully insured groups $(P<0.0001)$. In addition, the probability of retaining subscribers with a dependent aged 16 years or younger compared with all subscribers was significantly greater $(P<0.0001)$. The analysis also found the probability of retaining subscribers with a qualifying dependent with a rare disease compared with subscribers with any dependent aged 16 years or younger was significantly greater $(P<0.0001)$.

CONCLUSIONS: This study demonstrated that families with a child with a rare disease remained with their commercial health insurer longer than families who did not have a child with a rare disease. The analysis will be a useful resource when evaluating alternative payment arrangements and cost/benefit analyses of regenerative therapies that offer an extended duration of clinical benefit.

J Manag Care Spec Pharm. 2019;25(2):186-93

Copyright $\odot 2019$, Academy of Managed Care Pharmacy. All rights reserved.

\section{What is already known about this subject}

Insurers may perform retention studies to help in determinations associated with acquiring and retaining subscribers; but these may be performed on the overall membership base (not specific to rare disease), and policymakers may not have this information when making recommendations regarding coverage.

Families who have a child with a rare disease often have higher health care costs than families whose children do not have a rare disease.

Scientific advances create opportunities to produce long-lasting effects delivered by a single administration of gene or cell (regenerative) therapies.

\section{What this study adds}

This study produced robust estimates for the length of time that families and families with a child with a rare disease may remain with a given commercial health insurer.

Application of the retention results can be useful for policymakers and commercial health insurers when assessing therapies that may offer long-lasting effects delivered by a single administration. This study applied a methodology to assess an incomplete dataset where the exact enrollment and disenrollment dates may be unknown.

A dvances in fundamental science and medical biotechnology, creation of integrated delivery systems, expansion of coverage, and growth of alternate payment arrangements have produced rapid change in the health care system in the United States. ${ }^{1-4}$ Medical advancements have come in the form of diagnostic, radiologic, and surgical capabilities, but possibly more transformative are the innovations in pharmacologic, gene, and cell (regenerative) therapies, a majority of which are designed to address the root cause of various diseases. Some of these regenerative therapies are expected to result in an extended duration of clinical benefit delivered by a single administration.

The emerging advancements in pharmacologic treatments are particularly promising for certain rare diseases. A rare disease is one that affects fewer than 200,000 people in the United States. ${ }^{5}$ There are an estimated 7,000 rare diseases, only $5 \%$ of those have a treatment, and $80 \%$ are genetically based. ${ }^{6,7}$ 
Between 25 and 30 million Americans are living with a rare disease, with more than half of those affected being children. ${ }^{6,8}$ Many pediatric rare diseases may be debilitating or result in premature death. ${ }^{7}$

The Orphan Drug Act of 1983 promotes research and development of treatments for rare diseases. ${ }^{5}$ In the years since its passage, additional regulatory changes and guidelines have continued to promote the development of rare disease treatments. In 2017, the U.S. Food and Drug Administration approved 3 regenerative therapies, 2 of which are indicated to treat pediatric rare diseases. ${ }^{9-11}$

As treatments become more precise and specialized, the economics and underlying risks of discovery, clinical trials, and manufacturing may lead to therapies with an acquisition cost that is a multiple of the annual cost of chronic treatments and/or best supportive care. Health economists, innovators, policymakers, and academic-industry consortiums are actively researching alternate payment arrangements to address potential concerns about affordability and to ensure access to these regenerative therapies. ${ }^{12}$ Some proposed payment arrangements involve recognizing the duration of the clinical benefit regenerative therapies offer, which extend several years beyond the administration and potentially over a patient's lifetime. These approaches expose a challenge unique to the multipayer system in the United States: the payer who funds the treatment may not retain the subscriber for the entire time period that the clinical benefit accrues.

Health insurance coverage in the United States is a multifaceted system whereby coverage can be attained through a variety of avenues. Health insurance policies may be obtained through the individual market (i.e., individually purchased plan), government provided (i.e., Medicare or Medicaid), or commercially arranged (e.g., employer sponsored). The focus of this research was on the commercially insured portion that represents $60 \%$ of insured Americans, where the subscriber is the primary enrollee of a policy. ${ }^{13}$

The study investigators believe that insurers, policymakers, and government agencies in the United States may find it useful to have an accurate expectation for the length of enrollment by subscribers with a dependent who suffers from a pediatric rare disease and may be a candidate for a regenerative therapy with a potentially prolonged clinical benefit. Retention studies related to the commercially insured population are not widely available in the public domain. Although research has been conducted for the individual market, the dynamics related to that population are unique and do not extrapolate well to the commercial market. ${ }^{14}$ The investigators, therefore, performed this study to assess subscriber retention in the commercial market.

\section{Methods}

\section{Data Source}

This retrospective cohort study used data from 2007 to 2016 in the MarketScan Commercial Claims and Encounters research database, which reflects the health care experience of employees (subscribers) and dependents covered by the health benefit programs of large employers, health plans, and government organizations. These claims data are collected from approximately 350 health insurer contributors. The MarketScan Commercial Claims and Encounters research database includes data from active subscribers, early retirees, COBRA continuees, and dependents insured by employer-sponsored plans.

The data used were deidentified and complied with all aspects of the Health Insurance Portability and Accountability Act. Because this study only used deidentified records and did not involve the collection, use, or transmittal of individually identifiable data, institutional review board approval was not required.

The "Health Plan Indicator" field in the database was used to classify the contributors' experience into 2 groups: fully insured (e.g., health plans) and self-insured (e.g., large employers). The difference between fully insured and self-insured lies with the financial responsibility for an enrollee's health benefit claims. Employers shoulder the responsibility in self-insured plans and cede the financial responsibility to health plans in fully insured plans. ${ }^{15}$ For the fully insured and self-insured populations, subscribers represent 1-120 months of enrollment with their respective data contributors. The data contributors associated with the fully insured population contributed data for varying lengths of time over the 10 years. The majority of the fully insured subscriber data points were associated with contributors who provided 6 years of data $(n=25,529,444$, $65 \%$ ). The majority of the self-insured subscriber data points were associated with contributors who provided 10 years of data ( $n=11,572,264,59 \%)$. In the self-insured population, the contributors with the longest reporting represent large plans that have the greatest number of subscribers.

Within the MarketScan Commercial Claims and Encounters research database, subscribers and their dependents are uniquely identified so patient longitudinal analyses can be supported. Subscribers can be categorized based on the number and types of dependents associated with them (e.g., employee only or employee plus spouse). It is important to note that when referring to retention with an insurer, switching between types of coverage offered by the same insurer during the study period (e.g., switching from employee only to employee plus spouse) appears seamless in the data. Only changes from one insurer to another result in a subscriber's tenure ending with a given insurer.

\section{Cohorts}

For this retrospective analysis, 6 cohorts were created. Two cohorts included all subscribers observed during the study period (all subscribers), 1 from the fully insured population and 1 from the self-insured population. Two cohorts were subsets of all subscribers comprised of subscribers who had any 


\section{FIGURE 1 Examples of Subscriber Exposure Time Relative to Contributor Length}

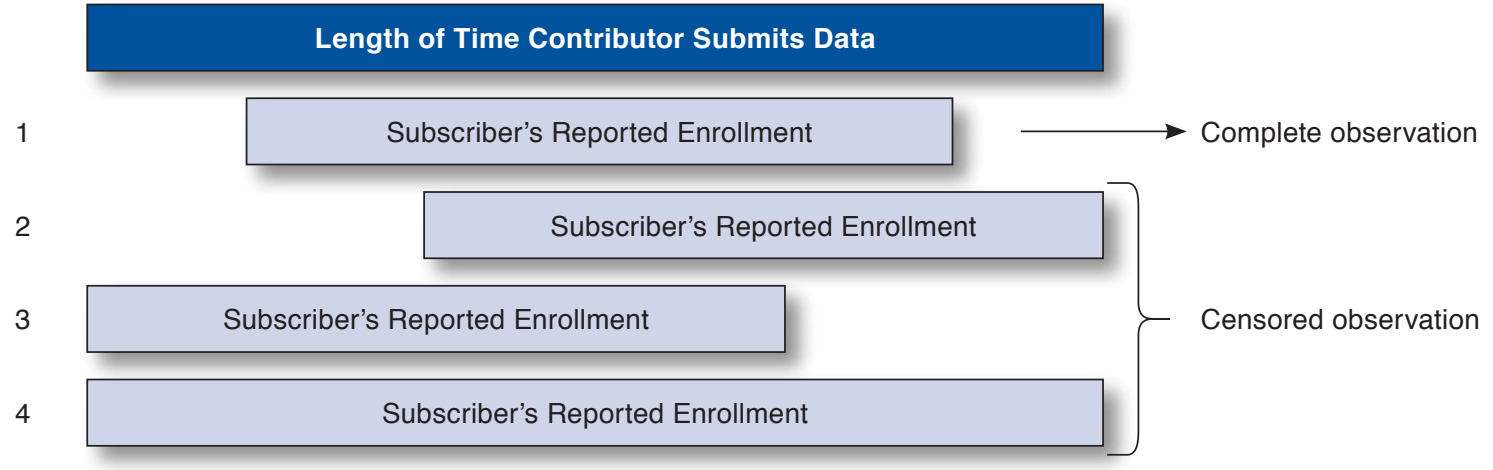

dependent aged 16 years or younger during the 10-year study period (all families). Again, 1 cohort was created from the fully insured population and 1 from the self-insured population. The last 2 cohorts were subsets of all families and represented families that have a child with a rare disease (families with a rare disease). These families were identified based on analysis of diagnosis code history for dependents aged 16 years or younger from the all families cohorts. Dependents were identified with any of the rare conditions if they had 2 occurrences with the included diagnosis codes at any time during the study period.

The medical conditions included in the study represent rare diseases that are chronic, affect infants and children, and result in a debilitating state or high mortality. The diagnosis codes used to identify the rare diseases included in the study can be found in Appendix A (available in online article). The conditions identified have high health care resource utilization, even if effective treatment is not available. These conditions also typically have a material effect on the child's quality of life, comorbidity, and/or life expectancy. The clinical conditions were selected before any analysis on the data to avoid selection bias based on the included conditions. The data collection period included the transition from use of the International Classification of Disease, Ninth Revision, Clinical Modification to International Classification of Disease, Tenth Revision, Clinical Modification (ICD-10-CM). Thus, the codes from both revisions were used. To ensure that all of the equivalent ICD10-CM codes were captured, the 2018 ICD-10-CM General Equivalence Mappings published by the Centers for Medicare $\&$ Medicaid Services was used.

The enrollment period for a subscriber in any of the family cohorts was initiated upon the first observation of the dependent and terminated upon the last observation of the subscriber. That is, even if coverage for a subscriber's dependent ended during the study period, if the subscriber remained with the data contributor, the subscriber was retained in the study.

\section{Study Approach and Statistical Analysis}

Health plans can conduct relatively straightforward retention studies because they have the benefit of a comprehensive set of data that includes complete enrollment information for all subscribers. This study used incomplete enrollment history because contributors to the MarketScan Commercial Claims and Encounters research database can change annually. A Kaplan-Meier estimator with imputation of interval-censored observations was used to produce retention rates for the cohorts.

Because of the nature of the research database used for this analysis, many observations were incomplete (censored). Enrollment for the subscribers could only be observed when a contributor submitted its experience. For example, within the fully insured population, 2 large contributors stopped submitting their data during this study period. The duration of their contribution during the study period was 6 years. Thus, the maximum amount of observable time for subscribers associated with those contributors was 6 years.

If a subscriber's enrollment ended coincident with the data contributor ending its data submissions, we could not verify whether the subscriber continued to be enrolled with the plan. Similarly, if a subscriber's enrollment began coincident with the data contributor first submitting its data, the subscriber could have have been enrolled before the start of data collection.

Figure 1 illustrates the potential ways in which the observations could be censored. The first example has complete experience. Examples 2 and 4 include subscribers who are censored at exit. No adjustment was made to account for the potential length of time they may have been enrolled subsequent to the associated contributor submitting experience to the research database. The Kaplan-Meier estimator effectively assumes that these subscribers have experience consistent with the pattern demonstrated by the observed subscriber experience. 
TABLE 1 Demographic Results for the Study Cohorts

\begin{tabular}{|c|c|c|c|c|c|c|c|c|c|c|}
\hline \multirow[b]{2}{*}{$\begin{array}{l}\text { Subscriber } \\
\text { Characteristics }\end{array}$} & \multicolumn{5}{|c|}{ Fully Insured } & \multicolumn{5}{|c|}{ Self-Insured } \\
\hline & $\begin{array}{c}\text { All } \\
\text { Subscribers }\end{array}$ & $\begin{array}{c}\text { All Families } \\
\text { Cohort }\end{array}$ & $P$ Value & $\begin{array}{c}\text { Families } \\
\text { with a Rare } \\
\text { Disease } \\
\text { Cohort }\end{array}$ & $P$ Value ${ }^{\mathrm{a}}$ & $\begin{array}{c}\text { All } \\
\text { Subscribers }\end{array}$ & $\begin{array}{c}\text { All } \\
\text { Families } \\
\text { Cohort }\end{array}$ & $P$ Value ${ }^{b}$ & $\begin{array}{c}\text { Families } \\
\text { with a Rare } \\
\text { Disease } \\
\text { Cohort }\end{array}$ & $P$ Value ${ }^{b}$ \\
\hline Observations, n (\%) & $39,274,850$ & $\begin{array}{c}9,904,563 \\
(25.2)\end{array}$ & & $\begin{array}{c}9,117 \\
(0.1)\end{array}$ & & $19,621,014$ & $\begin{array}{c}6,111,514 \\
(31.1)\end{array}$ & & $\begin{array}{c}6,904 \\
(0.1)\end{array}$ & \\
\hline $\begin{array}{l}\text { Observation } \\
\text { months, } \mathrm{n}\end{array}$ & $860,267,578$ & $262,736,479$ & & 322,336 & & $725,056,027$ & $274,254,793$ & & 410,601 & \\
\hline $\begin{array}{l}\begin{array}{l}\text { Average age of } \\
\text { subscriber, }{ }^{c} \text { years }\end{array} \\
\end{array}$ & 41.7 years & 39.5 years & $<0.0001$ & 39.6 years & 0.78 & 42.5 years & 40.0 years & $<0.0001$ & 40.5 years & $<0.0001$ \\
\hline Male, n (\%) & $\begin{array}{c}21,169,144 \\
(53.9)\end{array}$ & $\begin{array}{c}6,031,879 \\
(60.9)\end{array}$ & $<0.0001$ & $\begin{array}{l}6,081 \\
(66.7) \\
\end{array}$ & $<0.0001$ & $\begin{array}{l}10,497,243 \\
\quad(53.5) \\
\end{array}$ & $\begin{array}{c}3,636,350 \\
(59.5)\end{array}$ & $<0.0001$ & $\begin{array}{l}4,592 \\
(66.5) \\
\end{array}$ & $<0.0001$ \\
\hline $\begin{array}{l}\text { Include spouse on } \\
\text { coverage, } \mathrm{n}(\%)\end{array}$ & $\begin{array}{c}13,314,174 \\
(33.9)\end{array}$ & $\begin{array}{c}6,804,435 \\
(68.7) \\
\end{array}$ & $<0.0001$ & $\begin{array}{l}7,111 \\
(78.0) \\
\end{array}$ & $<0.0001$ & $\begin{array}{c}8,378,172 \\
(42.7)\end{array}$ & $\begin{array}{c}4,412,513 \\
(72.2) \\
\end{array}$ & $<0.0001$ & $\begin{array}{l}5,688 \\
(82.4) \\
\end{array}$ & $<0.0001$ \\
\hline $\begin{array}{l}\text { Average number of } \\
\text { dependents aged } \\
\leq 16 \text {, } \text { years }\end{array}$ & 0.5 & 1.8 & $<0.0001$ & 2.1 & $<0.0001$ & 0.6 & 1.8 & $<0.0001$ & 2.2 & $<0.0001$ \\
\hline $0(\%)$ & 74.8 & 0.0 & & 0.0 & & 68.9 & 0.0 & & 0.0 & \\
\hline $1(\%)$ & 11.5 & 45.8 & & 29.8 & & 13.6 & 43.7 & & 26.9 & \\
\hline $2(\%)$ & 9.2 & 36.3 & & 41.1 & & 11.6 & 37.3 & & 42.1 & \\
\hline $3+(\%)$ & 4.5 & 17.9 & & 29.2 & & 5.9 & 19.0 & & 31.0 & \\
\hline
\end{tabular}

aThe $P$ value is the result of the comparison of the all subscribers cohort to the all families cohort.

${ }^{b}$ The $P$ value is the result of the comparison of the all families cohort to the families with a rare disease cohort.

'The average age of each subscriber was calculated during their exposure period. The value reported in the table represents the average age for all subscribers in each cohort.

dThe maximum number of child dependents observed during the subscriber exposure period was associated with each subscriber. The value reported in this table represents the average number of child dependents assigned to subscribers in each cohort.

The third example includes subscribers who are censored only at entry. This is an example of a specific type of censoring called interval censoring. Interval censoring applies to instances where the actual enrollment date cannot be observed, but the range of enrollment dates can be reasonably estimated.

Interval censoring was only applied to subscribers in family cohorts to account for the actual enrollment date when it was not observed. Subscribers, with or without additional covered dependents, were included in all subscribers cohorts, and interval censoring was not applied. Because the enrollment period for a subscriber in the family cohorts begins when the dependent is first observed and the age of the oldest dependent is known $(x)$, the earliest (unobserved) enrollment date for the subscriber cannot exceed $x+1$ years before the inclusion in the database. (The additional year accounts for the first year of life.)

A log rank test with chi-square analysis was used to evaluate statistical significance between retention rates. Descriptive statistics were used to analyze demographic data. The sample size was sufficient to detect a statistically significant difference at $P=0.05$. The data analysis for this research was generated using SAS software LIFETEST Procedure (SAS Institute, Cary, NC).

\section{Results}

The fully insured cohorts included 39,274,850 subscribers. Twenty-five percent of the subscribers were included in the fully insured all families cohort. Of the families in the study, $9,117(0.1 \%)$ had a dependent child with at least 1 of the identified rare diseases. Table 1 includes the demographic results for the 2 study populations and the 3 cohorts within each population. Appendix B (available in online article) contains demographic information, like Table 1 , for each of the rare diseases studied.

The self-insured population represents a smaller group of subscribers within the data. The self-insured all subscribers cohort included 19,621,014 subscribers, and the all families cohort represented $31.1 \%$ of all subscribers. Of the families within the self-insured population, 6,904 (0.1\%) had a dependent child with at least 1 of the identified rare diseases.

For both populations, the proportion of subscribers who were male increased across the cohort spectrum and was lowest in the all subscribers cohorts and highest in the families with a rare disease cohorts. When assessing the proportion of observations where a spouse was included on the subscriber's plan, we see a similar trend across the cohorts for both types of insured populations.

When comparing the retention for each of the cohorts, the self-insured population had a longer retention, on average, than the fully insured population (Figure 2). It was also observed that the all families cohorts had a longer retention, 

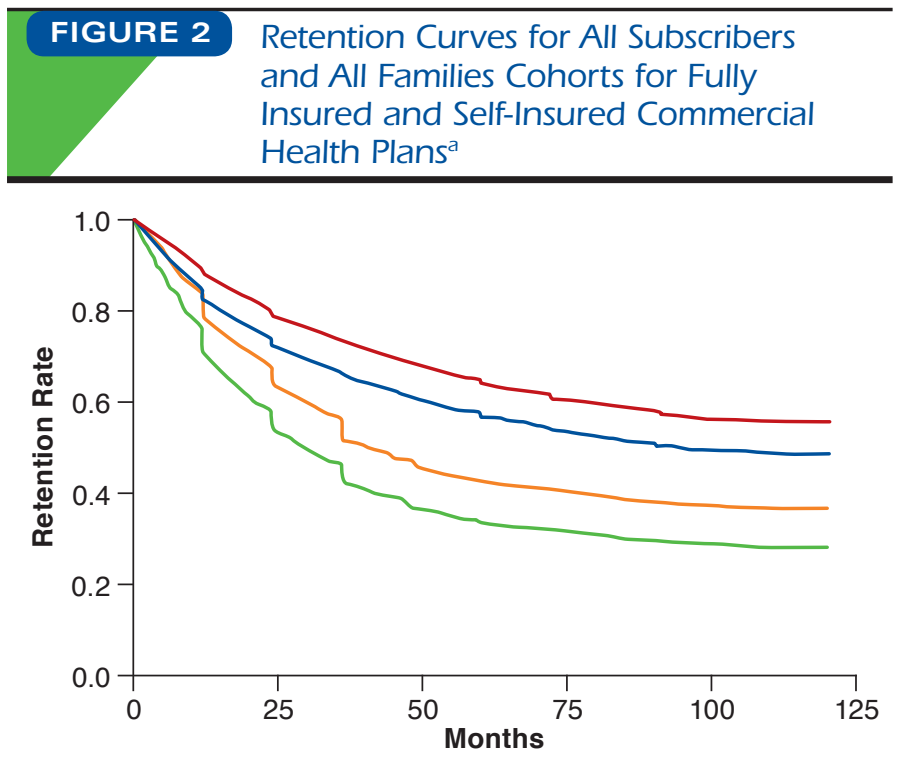

\section{- Self-Insured All Families \\ _ Self-Insured All Subscribers \\ _ Fully Insured All Families \\ _ Fully Insured All Subscribers}

aThe data informing these retention curves did not have interval censoring applied.

on average, compared with each of the all subscribers cohorts. The retention rates of self-insured all subscribers and fully insured all subscribers were statistically significantly different with $P<0.0001$. Also, the retention rates for the all families cohort and the all subscribers cohort, for each insured population, were statistically significantly different $(P<0.0001$ and $P<0.0001$, respectively). To make the comparison between the all subscribers and all families for each commercially insured population as equivalent as possible, interval censoring was not performed on all families data for this comparison.

Figure 3 depicts the retention rates for the all families and families with a rare disease cohorts for each commercially insured population. In both commercially insured populations, subscribers who had a dependent child with at least 1 of the rare diseases studied remained with their data contributors longer compared with the all families cohorts. The difference in the fully insured and self-insured populations were both statistically significant with $P<0.0001$ and $P<0.0001$, respectively. Interval censoring was applied to all 4 cohorts in Figure 3.

The retention for each of the 4 cohorts at common plan year anniversaries (e.g., 12, 24, and 36 months) can be seen in Table 2 . Within the fully insured population, retention at 5 and 10 years for families with a rare disease were $43.4 \%$ and $36.0 \%$, respectively, with an average retention of 62.7 months.

\section{FIGURE 3 Retention Curves for All Families and Families with a Rare Disease Cohorts for Fully Insured and Self-Insured Commercial Health Plans ${ }^{a}$}

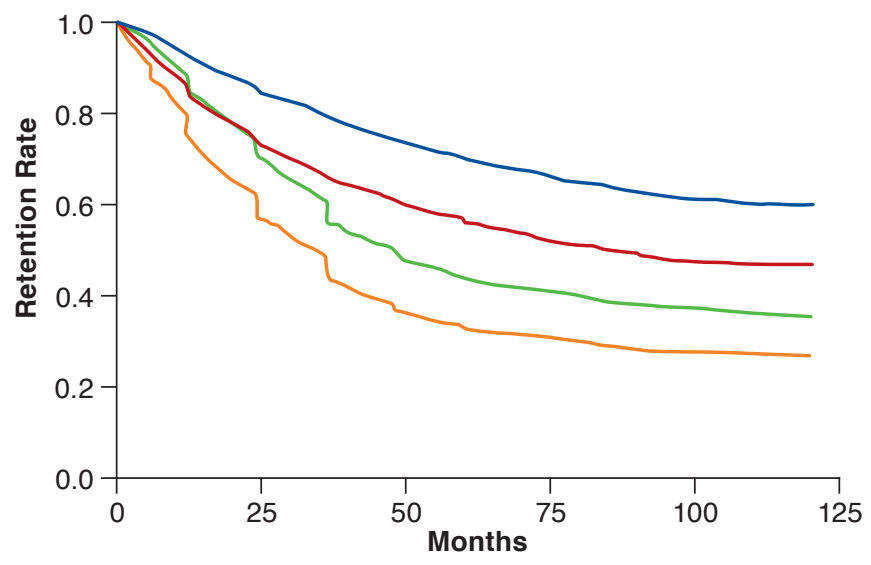

_ Self-Insured All Families with a Rare Disease
Self-Insured All Families
Fully Insured All Families with a Rare Disease
Fully Insured All Families

aThe curves in this figure pair with Table 2. Interval censoring was applied to the data.

Retention rates within the self-insured population were observed to be higher, with 5- and 10-year retention rates of $69.5 \%$ and $60.3 \%$, respectively, with an average retention of 84 months. It should be noted that the mean retention figures were underestimated because the largest observation was censored, and the estimation was restricted to the largest event time in the study, which was 10 years.

Additionally, an analysis compared the retention rate for each condition with that of the subscribers within the families with a rare disease cohort for the fully insured and self-insured populations. For the fully insured population, 3 rare diseases were observed to be statistically significantly different than the families with a rare disease cohort. These diseases were the lipidoses conditions (e.g., Gaucher disease), muscular dystrophy, and phenylketonuria (PKU). The retention for subscribers with a child with either a lipidoses condition or muscular dystrophy was observed to be longer, on average $(P=0.024$ and $P=0.0002$, respectively). However, retention was observed to be shorter for subscribers with a child diagnosed with PKU $(P=0.0079)$. Retention rates for Hunter syndrome, cystic fibrosis, Pompe disease, and spinal muscular atrophy were not different from that of subscribers within the families with a rare disease cohort.

Within the self-insured population, the retention of subscribers with a child with either muscular dystrophy or 


\begin{tabular}{l|c|c|c|c}
\hline \multirow{2}{*}{ TABLE 2 } & \multicolumn{3}{c}{$\begin{array}{c}\text { Retention Probability at Plan Year } \\
\text { Anniversaries for Families }\end{array}$} \\
\cline { 2 - 5 } & \multicolumn{2}{|c}{ Fully Insured } & \multicolumn{2}{c}{ Self-Insured } \\
\cline { 2 - 5 } & All Families & $\begin{array}{c}\text { Families } \\
\text { with a Rare } \\
\text { Disease }\end{array}$ & All Families & $\begin{array}{c}\text { Families } \\
\text { with a Rare } \\
\text { Disease }\end{array}$ \\
\hline 12 months & $74.2 \%$ & $84.8 \%$ & $83.8 \%$ & $92.0 \%$ \\
\hline 24 months & $57.4 \%$ & $70.3 \%$ & $73.1 \%$ & $84.5 \%$ \\
\hline 36 months & $43.8 \%$ & $56.2 \%$ & $65.9 \%$ & $79.0 \%$ \\
\hline 48 months & $36.7 \%$ & $48.5 \%$ & $60.2 \%$ & $73.7 \%$ \\
\hline 60 months & $32.6 \%$ & $43.4 \%$ & $55.9 \%$ & $69.5 \%$ \\
\hline 72 months & $31.3 \%$ & $41.6 \%$ & $52.4 \%$ & $66.6 \%$ \\
\hline 84 months & $28.9 \%$ & $38.8 \%$ & $50.0 \%$ & $63.8 \%$ \\
\hline 96 months & $27.9 \%$ & $37.4 \%$ & $47.8 \%$ & $61.7 \%$ \\
\hline 108 months & $27.3 \%$ & $36.6 \%$ & $47.1 \%$ & $60.4 \%$ \\
\hline $\begin{array}{l}120 \text { months } \\
\text { Average number } \\
\text { of months }\end{array}$ & $27.3 \%$ & $36.0 \%$ & $47.0 \%$ & $60.3 \%$ \\
\hline $\begin{array}{l}\text { aThe data in this table pair with Figure 3. Interval censoring was applied to the } \\
\text { data. }\end{array}$
\end{tabular}

PKU was observed, on average, to be different $(P=0.0002$ and $P=0.0049$, respectively) from the subscribers within the families with a rare disease cohort. As observed in the fully insured population, self-insured subscribers with a child diagnosed with muscular dystrophy remained longer, and subscribers with a child diagnosed with PKU were not retained as long, on average. The retention rates for subscribers with a child diagnosed with PKU more closely resembled the all families cohorts for the fully and self-insured populations. Retention rates for Hunter syndrome, cystic fibrosis, Pompe disease, spinal muscular atrophy, and Gaucher disease were not different from that of subscribers within the families with a rare disease cohort.

\section{Discussion}

The vast majority of the approximately 7,000 rare diseases have no treatment options. Eighty percent of rare diseases have a genetic basis, and since the enactment of the Orphan Drug Act, almost 450 drugs have been approved for the treatment of rare diseases. ${ }^{6,7,16}$ However, with advances in the understanding of the genetic basis of rare diseases and the advent of gene therapy, research companies are identifying and developing treatments. Some recently approved therapies for rare diseases, as well as others currently in clinical trials, are expected to provide significant improvement in a patient's condition lasting for years.

Yet, these groundbreaking therapies may have a high upfront price. Innovators, health insurers, and policymakers are researching alternate payment arrangements. A key element in this discussion is the consideration of health insurance subscriber retention. The length of subscriber retention may contribute to modeling and contracting for payment arrange- ments that continue past the year of therapy administration. This study provides robust estimates of subscriber retention within commercial health insurance for 3 populations: all subscribers, all families, and families with at least 1 dependent child with any of the studied rare diseases.

Analysis of the demographic results of each cohort demonstrated that the populations were sufficiently sized and ages were highly consistent across the cohorts. It has been estimated that $61 \%$ of all employees are covered under a self-insured plan; however, contributors to the MarketScan Commercial Claims and Encounters research database from 2007 to 2016 represent a larger portion of fully insured health insurers compared with self-insured..$^{13}$ The cohorts were studied independently and represented large samples of each population; therefore, the investigators do not believe the differences in sampling rates underlying the MarketScan Commercial Claims and Encounters database introduced any bias to the analysis.

The investigators anticipated that retention of subscribers in self-insured plans would be greater than those in fully insured plans. The findings of this study support that hypothesis. Selfinsured employers by definition have financial accountability for all of their employees' health benefit claims. They often look to find ways to reduce health care costs through network and benefit strategies and improve workforce productivity through care management programs, but they will less frequently change the third-party administrator. Thus, subscriber turnover is more likely the result of subscriber decisions and employment change. However, employers participating in fully insured health plans cede the financial responsibility for their employees' health benefit claims to the health plan. These employers are likely to be more price sensitive and change health plan carriers more frequently. Subscriber turnover in fully insured plans is, therefore, more likely to be a function of entire employer groups switching health plans rather than decisions by individual subscribers. This can also be seen by the larger drops at the first 3 plan-anniversary years (i.e., 12 months, 24 months, and 36 months).

Families, especially those with a child with a rare disease, may be more connected to a network of support ranging from health care providers to friends, extended family, and their community when compared with a subscriber who is single or not affected by a rare disease. The results of this study demonstrate that all families and families with a child who has 1 of the rare diseases studied remained with their insurer significantly longer than the average subscriber. The results also indicate that families who have a child with 1 of the rare diseases studied are retained even longer than the average family. This study was not designed to assess the rationale that families may use when making health insurance coverage decisions. Additional investigation via surveys and interviews could address the underlying factors involved. 
It is also important to note that the retention curve for each of the cohorts is steeper in the first 2-3 years and then flattens out. This finding can most easily be seen in the 3 cohorts within the fully insured commercial population and indicates that, even within an employer population that is price sensitive and has flexibility to change insurers, there is a significant number of subscribers who will be retained for at least 6 years. In the self-insured commercial population, a significant portion of subscribers will remain at least 10 years.

This study was a retrospective look at behaviors of subscribers with commercial health coverage over the past 10 years. As use of regenerative medicines grows, additional opportunities to assess effects of those therapies, including on retention, continue to be important.

\section{Limitations}

This study has some limitations to consider. Only trends for selected rare diseases were observed and analyzed. Other segments of the population, such as adults with a chronic disease, may experience different retention than all subscribers, since by its very definition, the all subscribers cohort was a reflection of the average retention observed.

The study period in this research overlapped with significant change in the commercial health care market. The Affordable Care Act (ACA) changed several factors that may have influenced the results. During this period, the lifetime maximum limit was removed and the dependent age cut-off was increased from age 18 years to age 26 years before a dependent would no longer be eligible to be covered on a parent's plan. Insurance coverage for pre-existing conditions also became a requirement. The sample size before and after the implementation of the ACA was unable to be assessed due to the phase-in portion for some of the changes resulting from the ACA.

Also, based on the nature of the data, some of the data were incomplete for subscribers. Censoring methods were applied to incomplete data.

As can be seen with the relatively high proportion of subscribers remaining with the data contributor for the duration of the study, this study likely underestimated the average length of time some subscribers may have been retained and could be considered conservative estimates.

This analysis was conducted on a robust sample of commercial health insurers. The actual experience for any health plan or employer may be different. The investigators anticipate that these findings will be compelling to health plans, employers, and policymakers and can inform the dialogue concerning payment policies for regenerative therapies in insured populations.

\section{Conclusions}

$\overline{\text { Advances in fundamental science, discovery, and biotechnol- }}$ ogy have led to breakthrough regenerative therapies, some with single administration, for rare diseases that currently require chronic treatment. These therapies have the potential to make a significant impact on the lives of individuals and their families, particularly children with a rare and often debilitating and fatal disease. Although the clinical interventions offer great promise, policymakers, biopharmaceutical companies, and payers are exploring how to make these treatments more accessible and affordable. Retention estimates for the commercially insured population in the United States may be a contributing factor in discussions about alternate payment arrangements and appropriate contract length among health insurers, policymakers, and manufacturers. This study demonstrates, in the commercially insured populations, that families who have a child with a rare disease remain with their health insurers significantly longer than families who do not have a child with a rare disease. This analysis will be a useful resource for stakeholders involved in evaluating alternate payment arrangements and cost-benefit analyses for regenerative therapies offering an extended duration of clinical benefit.

\section{Authors}

MELANIE K. KUESTER, PharmD, BCPS; E. ANNE JACKSON, FSA, MAAA; and BRENDA M. RUNYAN, MBA, Milliman, Indianapolis, Indiana. EDMUND J. PEZALLA, MD, MPH, enlightenment bioconsult, Wethersfield, Connecticut, and SAMUEL R. NUSSBAUM, MD, USC Schaeffer Center for Health Policy and Economics, Los Angeles, California.

AUTHOR CORRESPONDENCE: Melanie K. Kuester, PharmD, BCPS, Milliman, 10 W. Market St., Ste. 1600, Indianapolis, IN 46204. Tel.: 317.524.3528; E-mail: Melanie.Kuester@milliman.com.

\section{DISCLOSURES}

This study was sponsored by AveXis, which provided input into the study design, decided to submit the study results for publication, and performed an editorial review of the manuscript. Kuester, Jackson, and Runyan received consulting fees from AveXis during the conduct of this study. Pezalla and Nussbaum received consulting fees from Milliman during the conduct of this study. Nussbaum reports consulting fees from Sarepta Therapeutics and Ultragenyx Pharmaceutical outside of this study and serves on the Commercial Advisory Board of Gilead Sciences.

A variation on this topic was presented at the Academy of Managed Care Pharmacy Nexus 2018; October 22-25, 2018; Orlando, FL.

\section{ACKNOWLEDGMENTS}

The authors thank Luke Metz for his work in analyzing the large amount of data used in this study and Dave Liner for his review of the manuscript.

\section{REFERENCES}

1. Laiteerapong N, Huang ES. The pace of change in medical practice and health policy: collision or coexistence. J Gen Intern Med. 2015;30(6):848-52 
2. Health Care Payment Learning \& Action Network. Measuring progress: adoption of alternative payment models in commercial, Medicaid, Medicare Advantage, and fee-for-service Medicare Programs. October 30, 2017. Available at: https://hcp-lan.org/groups/apm-fpt-work-products/apm-report/. Accessed August 30, 2018.

3. Kaiser Family Foundation. Timeline: history of health reform. 2010. Available at: https://kaiserfamilyfoundation.files.wordpress.com/2011/03/502-13-history-of-health-reform.pdf. Accessed August 30, 2018.

4. Cigna. Health care reform timeline. Available at: https://www.cigna.com/ health-care-reform/timeline. Accessed August 30, 2018.

5. U.S. Food \& Drug Administration. Office of orphan products development. Updated July 9, 2018. Available at: https://www.fda.gov/ AboutFDA/CentersOffices/OfficeofMedicalProductsandTobacco/Officeof ScienceandHealthCoordination/ucm2018190.htm. Accessed August 30, 2018.

6. Genetic and Rare Diseases Information Center. FAQs about rare diseases. Updated November 30, 2017. Available at: https://rarediseases.info.nih.gov/ diseases/pages/31/faqs-about-rare-diseases. Accessed August 30, 2018.

7. Institute of Medicine. Rare Diseases and Orphan Products: Accelerating Research and Development. Washington, DC: The National Academies Press; 2010. Available at: https://www.nap.edu/catalog/12953/rare-diseases-andorphan-products-accelerating-research-and-development. Accessed August 30, 2018.

8. National Organization for Rare Disorders. Rare disease facts. Updated June 14, 2016. Available at: http://cdn.rarediseases.org/wordpresscontent/ wp-content/uploads/2014/11/NRD-1008-FactSheet_5.pdf. Accessed August 30, 2018.
9. U.S. Food \& Drug Administration. 2017 biological license application approvals. Updated April 3, 2018. Available at: https://www.fda.gov/ BiologicsBloodVaccines/DevelopmentApprovalProcess/BiologicalApprovals byYear/ucm547553.htm. Accessed August 30, 2018.

10. Kymriah (tisagenlecleucel) suspension for intravenous infusion. Novartis Corporation. May 2018. Available at: https://www.pharma.us.novartis.com/ sites/www.pharma.us.novartis.com/files/kymriah.pdf. Accessed August 30, 2018.

11. Luxturna (voretigene neparvovec-rzyl) intraocular suspension for subretinal injection. Spark Therapeutics. 2017. Available at: http://sparktx.com/ LUXTURNA_US_Prescribing_Information.pdf. Accessed August 30, 2018.

12. Hampson G, Towse A, Pearson SD, Dreitlein WB, Henshall C. Gene therapy: evidence, value, and affordability in the U.S. health care system. J Comp Eff Res. 2017;7(1):15-28.

13. Barnett JC, Berchick ER. Health insurance coverage in the United States: 2016. September 2017. Available at: https://www.census.gov/content/dam/ Census/library/publications/2017/demo/p60-260.pdf. Accessed August 30, 2018.

14. Pearson CF. Only 33 percent of exchange enrollees in 2016 kept their same plan from 2015. March 31, 2016. Available at: http://avalere.com/ expertise/managed-care/insights/only-33-percent-of-exchange-enrollees-in2016-kept-their-same-plan-from-201. Accessed August 30, 2018.

15. Henry J Kaiser Family Foundation. 2016 employer health benefits survey. September 14, 2016. Available at: https://www.kff.org/report-section/ ehbs-2016-section-ten-plan-funding/. Accessed August 30, 2018.

16. U.S. Food \& Drug Administration. Search orphan drug designations and approvals. Available at: https://www.accessdata.fda.gov/scripts/opdlisting/ oopd/. Accessed August 30, 2018. 


\section{APPENDIX A Medical Conditions Included in the Families with a Rare Disease Cohorts}

\begin{tabular}{|c|c|c|c|}
\hline General Description & Reference Name & ICD-9-CM Codes & ICD-10-CM Codes \\
\hline Mucopolysaccharoidoses conditions & Hunter & 277.5 & E76.x \\
\hline Glycogenosis conditions & Pompe & 271.0 & E74.0x, E74.4 \\
\hline Lipidoses conditions & Gaucher & 272.7 & E75.2x, E75.3, E77.x \\
\hline Spinal muscular atrophy & SMA & $335.0,335.10,335.11,335.19$ & G12.0, G12.1, G12.25, G12.8, G12.9 \\
\hline Phenylketonuria & PKU & 270.1 & E70.1, E70.0 \\
\hline Cystic fibrosis & $\mathrm{CF}$ & $277.00,277.01,277.02,277.03,277.09$ & E84.11, E84.19, E84.8, E84.9, E84.0 \\
\hline Muscular dystrophy & MD & 359.1 & G71.0 \\
\hline
\end{tabular}

ICD-9-CM = International Classification of Diseases, Ninth Revision, Clinical Modification; ICD-10-CM = International Classification of Diseases, Tenth Revision, Clinical Modification.

\section{APPENDIX B Demographic Results for the Families with a Rare Disease Cohorts}

\begin{tabular}{|c|c|c|c|c|c|c|c|}
\hline Subscriber Characteristics & Hunter & Pompe & Gaucher & SMA & PKU & $\mathrm{CF}$ & MD \\
\hline \multicolumn{8}{|l|}{ Fully insured cohort } \\
\hline Observations, n (\%) & $294 \quad(3.2)$ & $473 \quad(5.2)$ & $552 \quad(6.1)$ & $630 \quad(6.9)$ & $1,629(17.9)$ & $3,911(42.9)$ & $1,850(20.3)$ \\
\hline Observation months, $\mathrm{n}$ & 10,504 & 16,772 & 23,196 & 22,899 & 60,355 & 128,011 & 70,907 \\
\hline Average age of subscriber, years & 39.7 & 39.0 & 40.5 & 40.0 & 36.4 & 39.7 & 41.9 \\
\hline Male, n (\%) & $219(74.4)$ & $306(64.7)$ & $338(61.2)$ & $439(69.7)$ & $1,109(68.1)$ & $2,573(65.8)$ & $1,239(67.0)$ \\
\hline Include spouse on coverage, n (\%) & $239(81.3)$ & $362(76.5)$ & $427(77.4)$ & $521(82.7)$ & $1,274(78.2)$ & $3,000(76.7)$ & $1,461.5(79.0)$ \\
\hline Average number of dependents aged $\leq 16$ years & 2.2 & 2.2 & 2.1 & 2.1 & 2.2 & 2.1 & 2.2 \\
\hline $0(\%)$ & 0.0 & 0.0 & 0.0 & 0.0 & 0.0 & 0.0 & 0.0 \\
\hline $1(\%)$ & 27.6 & 27.1 & 29.9 & 33.0 & 30.2 & 30.2 & 28.9 \\
\hline $2(\%)$ & 41.8 & 43.6 & 42.0 & 37.8 & 36.7 & 42.8 & 40.3 \\
\hline $3+(\%)$ & 30.6 & 29.4 & 28.1 & 29.2 & 33.1 & 27.0 & 30.7 \\
\hline \multicolumn{8}{|l|}{ Self-insured cohort } \\
\hline Observations, n (\%) & $219 \quad(3.2)$ & $403 \quad(5.8)$ & $440 \quad(6.4)$ & $502 \quad(7.3)$ & $1,146(16.6)$ & $2,901(42.0)$ & $1,526(22.1)$ \\
\hline Observation months, $\mathrm{n}$ & 13,786 & 25,384 & 29,699 & 30,355 & 64,733 & 165,771 & 98,825 \\
\hline Average age of subscriber, years & 41.0 & 41.1 & 41.2 & 40.8 & 37.2 & 40.6 & 42.7 \\
\hline Male, n (\%) & $164(74.9)$ & $263(65.2)$ & $298(67.8)$ & $327(65.1)$ & $733(64.0)$ & $1,923(66.3)$ & $1,036(67.9)$ \\
\hline Include spouse on coverage, n (\%) & $189(86.3)$ & $321(79.7)$ & $383(87.0)$ & $416(82.9)$ & $932(81.3)$ & $2,393(82.5)$ & $1,256(82.3)$ \\
\hline Average number of dependents aged $\leq 16$ years & 2.2 & 2.3 & 2.2 & 2.2 & 2.2 & 2.2 & 2.3 \\
\hline $0(\%)$ & 0.0 & 0.0 & 0.0 & 0.0 & 0.0 & 0.0 & 0.0 \\
\hline $1(\%)$ & 26.0 & 27.5 & 24.8 & 26.1 & 26.7 & 27.0 & 26.7 \\
\hline $2(\%)$ & 46.6 & 40.4 & 44.8 & 42.2 & 41.2 & 42.6 & 41.3 \\
\hline $3+(\%)$ & 27.4 & 32.0 & 30.5 & 31.7 & 32.1 & 30.3 & 32.0 \\
\hline
\end{tabular}

